\title{
THE SCALE OF THE SOLAR SYSTEM
}

\author{
BY THE STAFF, MILLSTONE RADAR OBSERVATORY, LINCOLN LABORATORY*, \\ MASSACHUSETTS INSTITUTE OF TECHNOLOGY, \\ WESTFORD, MASSACHUSETTS
}

\begin{abstract}
TTHE close approach of Venus during April 1961 has permitted a re-determination of the scale of the solar system by means of radar distance measurements of this planet. Previously, measurements of this kind have been made by Price et $a l^{1}$ and Evans and Taylor ${ }^{2}$. These earlier experiments led to a value for the solar parallax of $\pi=8.8022 \pm 0.0001$ sec. of arc. This is not in agreement with new measurements made using the Millstone Radar Observatory of the Massachusetts Institute of Technology, Lincoln Laboratory, located at Westford, Massachusetts, in March and April 1961.
\end{abstract}

In all the experiments the transmitter is operated for a period somewhat longer than the two-way travel time. Following the transmission interval (usually about 5 min.) the received energy is integrated at different range-intervals for a duration corresponding to the echo time. In this way most possible sources of spurious echoes are removed. Allowance is made in the summation process for the gradual drifting of range with time. A display of the results of thirty such 'runs' for April 8 is shown in Fig. 1. Included in the processing is a calibration pulse, chosen to approximate the expected intensity of the

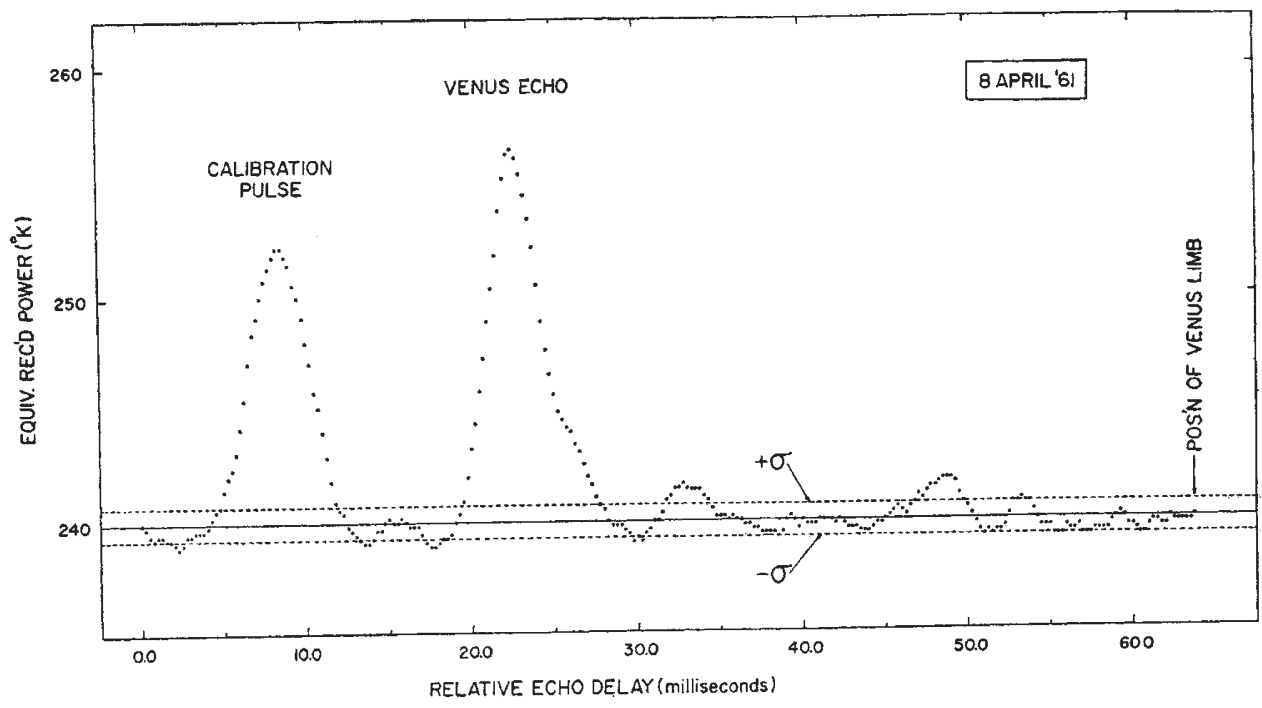

Fig. 1

This equipment operates with the following parameters: frequency, $440 \mathrm{Mc} . / \mathrm{s}$; ; aerial gain, $37.5 \mathrm{db}$.; peak transmitter power, 2.5 MW.; receiver noise temperature, $240^{\circ} \mathrm{K}$.; transmitter pulse-lengths, $0.5,2$, or 4 msec. The transmitter interpulse period has been varied at approximately daily intervals during the course of experiments which began on March 6. In this way the uncertainty in the total number of interpulse periods in the time for the pulse to travel the two-way distance to and from Venus can be removed. The value for the range of the planet has been converted to a value for the solar parallax by using an ephemeris computed in a manner described by Pettengill and Price ${ }^{3}$. The preliminary value obtained from twenty independent experiments conducted during the period March 6April 12 is :

$$
\pi=8.79450 \pm 0.00008 \text { sec. of arc }
$$

which corresponds to a mean solar distance of $149,597,700 \pm 1,500 \mathrm{~km}$. The observations are being continued and it is expected that a final analysis of all the measurements will yield a value substantially more accurate than the new value reported here.

* Operated with support from the U.S. Air Force.
Venus echo. The Venus echo may be seen to rise some 23 standard deviations above the mean noiselevel. The echo intensity corresponds to a received power-level of $163 \mathrm{db}$. below $1 \mathrm{~mW}$.

From the intensity of the echo we conclude that Venus scatters about 12 per cent of the incident energy. This is not greatly different from the amount scattered by the Moon ( 7 per cent, ref. 4) and suggests that Venus has a solid surface.

A frequency analysis of the returned signal power discloses very little spectral broadening. Two 4-min. runs analysed to date show that essentially all the returned power is contained within a band-width of less than one cycle per sec. Until some measure of the angular scattering law is obtained it is impossible to determine the planetary rotation. It is interesting, to note, however, that if one assumes an angular distribution similar to the Moon, an apparent rotational period consistent with the synodic period (584 days) is obtained.

1 Price, R., Green, P. E., Goblick, T. J., Kingston, R. H., Kraft, jun., L. G., Pettengill, G. H., Silver, R., and Smith, W.' B., Science, 129, 751 (1959).

2 Evans, J. V., and Taylor, G. N., Nature, 184, 1358 (1959).

${ }^{3}$ Pettengill, G. H., and Price, R., Planetary and Space Science, 5, 70 (1961).

${ }^{4}$ Fricker, S. J., Ingalls, R. P., Mason, W. C. Stone, M. L., and Swift, D. W., J. Research (Nat. Bur. Stand.), 64 D, 455 (1960). 